\title{
Effect of Phosphate and Sulfate on Ni Repartitioning During Fe(II)-Catalyzed
} Fe(III) Oxide Mineral Recrystallization

3

4

5

6

\author{
Margaret A. G. Hinkle* and Jeffrey G. Catalano
}

Department of Earth and Planetary Sciences, Washington University, 1 Brookings Drive, Saint Louis, MO 63130 USA

*Corresponding author: Tel.: +1 314-935-4922; Fax: +1 314-935-7361; E-mail:

mhinkle@eps.wustl.edu
Submitted to Geochimica et Cosmochimica Acta

January 2015

Revised April 2015 
Dissolved Fe(II) activates coupled oxidative growth and reductive dissolution of Fe(III)

17 oxide minerals, causing recrystallization and the repartitioning of structurally-compatible trace

18 metals. Phosphate and sulfate, two ligands common to natural aquatic systems, alter Fe(II)

19 adsorption onto Fe(III) oxides and affect Fe(III) oxide dissolution and precipitation. However,

20 the effect of these oxoanions on trace metal repartitioning during Fe(II)-catalyzed Fe(III) oxide

21 recrystallization is unclear. The effects of phosphate and sulfate on $\mathrm{Ni}$ adsorption and $\mathrm{Ni}$

22 repartitioning during Fe(II)-catalyzed Fe(III) oxide recrystallization were investigated as such

23 repartitioning may be affected by both Fe(II)-oxoanion and metal-oxoanion interactions. In most

24 systems examined, phosphate alters Ni repartitioning during Fe(II)-catalyzed recrystallization to

25 a larger extent than sulfate. Phosphate substantially enhances Ni adsorption onto hematite but

26 decreases (nearly inhibiting) Fe(II)-catalyzed Ni incorporation into and release from this mineral.

27 In the goethite system, however, phosphate suppresses Ni release but enhances Ni incorporation

28 in the presence of aqueous Fe(II). In contrast, sulfate has little effect on macroscopic Ni

29 adsorption and release of $\mathrm{Ni}$ from $\mathrm{Fe}(\mathrm{III})$ oxides, but substantially enhances Ni incorporation into

30 goethite. This demonstrates that phosphate and sulfate have unique, mineral-specific interactions

31 with Ni during Fe(II)-catalyzed Fe(III) oxide recrystallization. This research suggests that

32 micronutrient bioavailability at redox interfaces in hematite-dominated systems may be

33 especially suppressed by phosphate, while both oxoanions likely have limited effects in goethite-

34 rich soils or sediments. Phosphate may also exert a large control on contaminant fate at redox

35 interfaces, increasing Ni retention on iron oxide surfaces. These results further indicate that trace

36 metal retention by iron oxides during lithification and later repartitioning during diagenesis may

37 be substantially altered in the presence of oxoanions. 


\section{INTRODUCTION}

Fe(III) oxide minerals are prevalent in modern and ancient soils and sediments (Cornell and Schwertmann, 2003) and often control the concentrations of trace elements through

41 adsorption processes (Brown et al., 1999; Brown and Parks, 2001). The biogeochemical cycling

42 of Fe results in the coexistence of aqueous $\mathrm{Fe}(\mathrm{II})$ and solid Fe(III) oxides at redox interfaces in

43 natural aquatic systems. Such Fe cycling activates secondary abiotic reactions between aqueous

$44 \mathrm{Fe}(\mathrm{II})$ and solid $\mathrm{Fe}(\mathrm{III})$ oxides, involving the oxidative adsorption of $\mathrm{Fe}(\mathrm{II})$ and the subsequent

45 reduction of a structural $\mathrm{Fe}(\mathrm{III})$ cation elsewhere on the surface via interfacial electron transfer

46 and atom exchange (ET-AE) processes (Williams and Scherer, 2004; Larese-Casanova and

47 Scherer, 2007; Yanina and Rosso, 2008; Handler et al., 2009; Gorski and Scherer, 2011; Handler

48 et al., 2014). Fe(II)-Fe(III) ET-AE reactions result in spatially separated growth and dissolution,

49 leading to self-recrystallization of crystalline Fe(III) oxides (Handler et al., 2009; Catalano et al.,

50 2010; Handler et al., 2014), Fe isotope fractionation and equilibration (Pedersen et al., 2005;

51 Crosby et al., 2005; Wu et al., 2010; Beard et al., 2010), and metastable Fe oxide phase

52 transitions (Hansel et al., 2003; Hansel et al., 2004; Pedersen et al., 2005; Hansel et al., 2005;

53 Yang et al., 2010).

Previous work has shown that the presence of aqueous Fe(II) leads to the incorporation of

55 structurally compatible trace elements, such as Ni (Frierdich et al., 2011), into goethite and

56 hematite. Conversely, Fe(II) also causes the release to solution of trace metals preincorporated

57 into Fe(III) oxides (Latta et al., 2012b; Frierdich and Catalano, 2012). This dynamic

58 Fe(II)-catalyzed trace element cycling scales with Fe(II) surface coverage (Frierdich and

59 Catalano, 2012), and is fundamentally the result of Fe(III) oxide mineral recrystallization

60 (Pedersen et al., 2005; Handler et al., 2009; Latta et al., 2012b; Gorski et al., 2012; Frierdich et 
al., 2014).

$\mathrm{Fe}(\mathrm{III})$ oxide recrystallization, dissolution, and precipitation processes are affected by

63 phosphate and sulfate (Bondietti et al., 1993; Stumm, 1997; Eggleston et al., 1998; Majzlan and

64 Myneni, 2005; Borch et al., 2007), two oxoanions common in natural aquatic systems. Isotope

65 tracer experiments show that phosphate enhances the extent of $\mathrm{Fe}(\mathrm{II})-\mathrm{Fe}(\mathrm{III})$ atom exchange with

66 goethite (Latta et al., 2012a). Recent research shows that both sulfate and phosphate enhance

$67 \mathrm{Fe}(\mathrm{II})$ adsorption onto hematite and goethite through a combination of ternary complexation and

68 electrostatic interactions, with the specific interaction dependent on both mineral and oxoanion

69 identity (Hinkle et al., 2015). Processes associated with ET-AE reactions may thus be affected

70 differently by phosphate and sulfate and vary with iron mineralogy.

71 In this study, we examine how phosphate and sulfate alter Ni repartitioning during

72 Fe(II)-catalyzed Fe(III) oxide recrystallization. To identify how phosphate and sulfate alter Ni

73 redistribution during Fe(III) oxide recrystallization, the effect of these oxoanions on

74 Fe(II)-catalyzed Ni release from and incorporation into hematite and goethite was studied. The

75 effect of phosphate and sulfate on macroscopic $\mathrm{Ni}$ adsorption was also investigated, as $\mathrm{Ni}$

76 adsorption is an important intermediate during Ni incorporation into and release from Fe oxides

77 and oxoanions often enhance the adsorption of divalent metal cations, e.g., $\mathrm{Cd}, \mathrm{Co}, \mathrm{Cu}, \mathrm{Fe}, \mathrm{Pb}$,

78 and Zn (Benjamin and Bloom, 1981; Balistrieri and Murray, 1982; Diaz-Barrientos et al., 1990;

79 Madrid et al., 1991; Hoins, 1993; Venema et al., 1997; Collins et al., 1999; Jeon et al., 2001;

80 Juang and Wu, 2002; Swedlund et al., 2003; Hinkle et al., 2015). Ni partitioning between

81 adsorbed, incorporated, and aqueous Ni phases was determined through combined X-ray

82 absorption fine structure (XAFS) spectroscopy and mass balance calculations. 
2. MATERIALS AND METHODS

\subsection{Fe Oxide Preparation}

Pure and Ni-substituted hematite and goethite (Hem, NiHem, Goe, and NiGoe,

87 respectively) were prepared following previously published syntheses (Frierdich et al., 2011;

88 Hinkle et al., 2015), modified from the procedures described in Schwertmann and Cornell

89 (2000). After synthesis, Hem and Goe were rinsed and filtered with deionized (DI) water (>18.2

$90 \mathrm{M} \Omega \cdot \mathrm{cm})$ to remove excess electrolytes. The NiHem and NiGoe were filtered and washed with

$91 \quad 0.25 \mathrm{M} \mathrm{HCl}$ for two hours to remove adsorbed $\mathrm{Ni}$, and were then rinsed and filtered with DI

92 water to remove excess electrolytes. The iron oxides were resuspended in DI water and stored in

93 polypropylene bottles wrapped in aluminum foil.

94 The mineral suspensions were subsequently moved to an anaerobic chamber (Coy

95 Laboratory Products, Inc., $3 \% \mathrm{H}_{2} / 97 \% \mathrm{~N}_{2}$ atmosphere with Pd catalysts) and sparged with the

96 anaerobic chamber atmosphere, as described elsewhere (Hinkle et al., 2015). The mineral

97 suspensions were sparged until a colorimetric indicator test (CHEMets ${ }^{\circledR}$ Kit K-7540) indicated

98 that dissolved $\mathrm{O}_{2}$ was below the detection limit $\left(2.5 \mu \mathrm{g} \mathrm{\textrm {L } ^ { - 1 }}\right)$. A portion of each mineral

99 suspension was then dried at $70{ }^{\circ} \mathrm{C}$ for mineral characterization by BET analysis $\left(\mathrm{N}_{2}\right.$ adsorption,

100 Quantachrome Instruments Autosorb-1) for surface area determination, powder X-ray diffraction

101 (XRD; Bruker D8 Advance X-ray diffractometer, $\mathrm{Cu} \mathrm{K} \mathrm{K}_{\alpha}$ radiation) for phase identification, and

102 fractional and total acid dissolution [described in past research (Frierdich et al., 2011)] for the

103 distribution and extent of Ni substitution. Fluorescence-yield Ni K-edge XAFS spectra were

104 obtained for NiHem and NiGoe wet pastes to ensure consistency with previously published

105 works (Frierdich et al., 2011); the preparation of these samples and collection of these

106 measurements are described below. 


\subsection{Stock Solution Preparation}

An $\mathrm{Fe}(\mathrm{II})$ stock solution was prepared from $\mathrm{FeCl}_{2} \cdot 4 \mathrm{H}_{2} \mathrm{O}$ in the anaerobic chamber using

110 deoxygenated DI water, acidified to $\mathrm{pH} 2$ with $\mathrm{HCl}$, and stored in amber polypropylene bottles to

111 prevent photo-oxidation. $\mathrm{Na}_{2} \mathrm{HPO}_{4}, \mathrm{Na}_{2} \mathrm{SO}_{4}, \mathrm{NiCl}_{2}, \mathrm{NaCl}$, and 3-(N-morpholino)propanesulfonic

112 acid hemisodium salt (MOPS) buffer stock solutions were also prepared in the anaerobic

113 chamber using deoxygenated $\mathrm{DI}$ water. $\mathrm{HCl}$ and $\mathrm{NaOH}$ solutions for $\mathrm{pH}$ adjustments were

114 transferred to and sparged in the anaerobic chamber more than 90 days before use.

115

\subsection{Macroscopic Ni Adsorption Experiments}

117 The effect of phosphate and sulfate on Ni adsorption onto Fe(III) oxides was investigated

118 through a series of adsorption experiments. The experiments consisted of $1 \mathrm{~g} \mathrm{~L}^{-1} \mathrm{Hem}$ (or Goe)

119 reacted 0 or $0.1 \mathrm{mM}$ phosphate (or sulfate), $10 \mathrm{mM} \mathrm{NaCl}$ (for ionic strength buffering), $1.0 \mathrm{mM}$

120 MOPS buffer, and varying initial $\mathrm{Ni}$ concentrations at $\mathrm{pH} 7.00 \pm 0.05$. The experiments were

121 also conducted with mineral-free blanks to assess systematic errors in the initial $\mathrm{Ni}$

122 concentrations and in triplicate for samples reacted with an initial $100 \mu \mathrm{M} \mathrm{Ni}$. The samples were

123 prepared by adding phosphate (or sulfate), $\mathrm{NaCl}$, MOPS buffer, and $\mathrm{Ni}$ to the appropriate amount

124 of deoxygenated DI water in $15 \mathrm{~mL}$ conical centrifuge tubes. An aliquot of Hem (or Goe)

125 suspension was then added to the sample, marking the start of the reaction, and the $\mathrm{pH}$ of the

126 sample was adjusted to $\mathrm{pH} 7.00 \pm 0.05$ using $\mathrm{HCl}$ or $\mathrm{NaOH}$. The centrifuge tubes were rotated on

127 end-over-end rotators for five days while wrapped in aluminum foil. The sample $\mathrm{pH}$ was

128 checked and adjusted if necessary after 24 hours reaction time. After 5 days of reaction, the $\mathrm{pH}$

129 of each sample was recorded and the samples were filtered (0.22 $\mu \mathrm{m}$ MCE filters; Fisher 
130 Scientific), discarding the first $1 \mathrm{~mL}$ of filtrate. The samples were removed from the anaerobic

131 chamber and immediately acidified to $2 \% \mathrm{HNO}_{3}$ (trace metal grade; Fisher Scientific) for

132 inductively coupled plasma-optical emission spectroscopic (ICP-OES; Perkin Elmer Optima

1337300 DV) analysis for dissolved P and Ni concentrations. Sulfate concentrations were measured

134 by ion chromatography (IC; Metrohm 881 Compact IC Pro), with samples acidified to $0.5 \% \mathrm{HCl}$

135 (trace metal grade; Fisher Scientific). The sample uncertainty (95\% confidence level) was

136 calculated for ICP-OES analyses using the triplicate samples and the instrument triplicate

137 measurements.

\section{$139 \quad 2.4$ Ni Release Experiments}

140 The rate and extent of $\mathrm{Fe}(\mathrm{II})$-catalyzed Ni release from NiHem and NiGoe in the absence

141 and presence of phosphate and sulfate were probed by macroscopic Ni release and X-ray

142 absorption near edge structure (XANES) spectroscopy, heretofore collectively referred to as "Ni

143 release experiments." The macroscopic Ni release experiments were conducted following the

144 protocol outlined in Frierdich and Catalano (2012): each sample consisted of $1 \mathrm{~g} \mathrm{~L}^{-1} \mathrm{NiHem}$ (or

145 NiGoe), $10 \mathrm{mM} \mathrm{NaCl}, 1.0 \mathrm{mM}$ MOPS buffer, and 0 or $1.0 \mathrm{mM} \mathrm{Fe(II),} \mathrm{with} \mathrm{samples} \mathrm{reacted} \mathrm{for} 1$

146 hour, 3 hours, 1 day, 2 days, 3 days, 5 days, 8 days, and 14 days. Experiments employed 0 or 0.1

$147 \mathrm{mM}$ phosphate (or sulfate) concentrations; the 14 days samples were prepared in triplicate. The

148 samples were prepared by adding deoxygenated DI water with the appropriate aliquots of $\mathrm{NaCl}$,

149 MOPS buffer, $\mathrm{Fe}(\mathrm{II})$, and phosphate (or sulfate). The solutions were adjusted to $\mathrm{pH} 7.00 \pm 0.05$.

150 The appropriate amount of NiHem or NiGoe was then added to the solution, marking the

151 beginning of the experiment. Sample $\mathrm{pH}$ was checked and adjusted for drift if necessary. The

152 samples were then wrapped in aluminum foil and placed on an end-over-end rotator. At the end 
153 of the prescribed reaction time, the sample $\mathrm{pH}$ was recorded and the sample was filtered using

$1540.22 \mu \mathrm{m}$ MCE filters (Fisher Scientific). The filtrate samples were acidified and analyzed for

155 dissolved $\mathrm{Fe}, \mathrm{Ni}$, and $\mathrm{P}$ concentration with ICP-OES and sulfate concentrations with IC

156 following the procedures outlined in the previous section. The macroscopic Ni release data were

157 fit using a second order kinetic model (Electronic Annex), using the approach described by

158 Frierdich and Catalano (2012). To determine how solid-associated Ni partitioning is altered

159 during Ni release in the presence of oxoanions, large batches of the 14 day samples equilibrated

160 at $\mathrm{pH} 7.5$ (to increase the possibility of detecting adsorbed $\mathrm{Ni}$, if present) were filtered and

161 prepared following procedures described below for XAFS spectroscopic measurements. Previous

162 research indicates that increasing $\mathrm{pH}$ from 7 to 8 does not alter overall macroscopic Ni release

163 from NiGoe (Frierdich and Catalano, 2012), thus overall macroscopic Ni release likely exhibits

164 the same behavior at $\mathrm{pH} 7$ and 7.5 .

165

166

\subsection{Ni Incorporation Experiments}

167 The effect of sulfate and phosphate on $\mathrm{Ni}$ incorporation into Hem and Goe in the

168 presence of aqueous $\mathrm{Fe}(\mathrm{II})$ was investigated following a previously published procedure

169 (Frierdich et al., 2011). In these experiments, $4 \mathrm{~g} \mathrm{~L}^{-1} \mathrm{Hem}$ or Goe was reacted with a solution

170 consisting of $0.2 \mathrm{mM} \mathrm{Ni}, 10 \mathrm{mM} \mathrm{NaCl}, 1.0 \mathrm{mM}$ MOPS buffer, and varying concentrations of

$171 \mathrm{Fe}(\mathrm{II})$, sulfate or phosphate at $\mathrm{pH} 7.50 \pm 0.05$ for 30 days. The sulfate experiment samples were

172 reacted with $1.0 \mathrm{mM} \mathrm{Fe}(\mathrm{II})$ and $0,0.1$, or $1.0 \mathrm{mM}$ sulfate to maintain consistency with previous

173 research on aqueous Fe(II)-oxoanion-Fe(III) oxide systems conducted under similar conditions

174 (Hinkle et al., 2015). To prevent the precipitation of secondary mineral phases (e.g., vivianite),

175 the phosphate samples were reacted with lower Fe(II) and oxoanion concentrations: $0.5 \mathrm{mM}$ 
$176 \mathrm{Fe}(\mathrm{II})$ and $0,0.1$, or $0.5 \mathrm{mM}$ phosphate. At the end of the experiment, the suspensions were

177 filtered and prepared for XAFS spectroscopic measurements following the procedures described

178 below, while the filtrate was collected for ICP-OES analysis. These experiments will be referred

179 to as "Ni incorporation experiments" throughout the paper.

\subsection{XAFS Spectroscopic Measurements}

Fluorescence-yield Ni K-edge XAFS spectra were collected for samples from the Ni

183 release and Ni incorporation experiments, as well as end-member standards: NiHem, NiGoe, and

184 Ni adsorbed onto Hem and Goe in the presence of sulfate and phosphate. For comparison to the 185 two different sets of experiments, Ni adsorbed samples were prepared by reacting the maximum 186 concentration of phosphate (or sulfate) and the appropriate concentration of Hem (or Goe) for the 187 applicable experiment with $0.2 \mathrm{mM} \mathrm{Ni}, 10 \mathrm{mM} \mathrm{NaCl}$, and $1.0 \mathrm{mM}$ MOPS buffer for 5 days. The 188 samples were filtered (reusable syringe filter; $0.22 \mu \mathrm{m} \mathrm{MCE} \mathrm{membrane;} \mathrm{Fisher} \mathrm{Scientific)} \mathrm{to}$ 189 collect both filtered solids and filtrate. The filtered solids were packed as wet pastes in 190 polycarbonate sample holders, sealed with $25 \mu \mathrm{m}$ Kapton tape, and heat sealed in polyethylene 191 bags to maintain anoxic conditions. Samples were prepared within 48 hours of transport to the 192 Advanced Photon Source (APS) at Argonne National Laboratory. XAFS spectra of samples the 193 standard for the Ni release experiments were collected at beamline 12-BM-B, while XAFS 194 measurements for the Ni incorporation experiment XAFS were made at beamline 9-BM-C. Both 195 beamlines employ Si (111) fixed-offset double-crystal monochromators, which were detuned $19630 \%$ to reduce the harmonic content of the incident X-ray beam, as well as torroidal focusing and 197 flat harmonic rejection mirrors. The monochromators were calibrated at the Ni K-edge $(8333 \mathrm{eV})$ 198 using a Ni metal foil. Fluorescence-yield spectra were collected using a 12-element energy 
dispersive Ge detector.

\subsection{Analysis of XAFS Spectra}

XAFS spectra were averaged and normalized using IFEFFIT (Newville, 2001) via the

203 Athena interface (Ravel and Newville, 2005). Linear combination fitting (LCF) of normalized

204 XANES spectra was performed using Athena, with Ni-substituted hematite and goethite (NiHem 205 and NiGoe) and Ni adsorbed onto pure hematite (Hem) and goethite (Goe) as end-member

206 standards. The $\mathrm{k}^{3}$-weighted extended X-ray absorption fine structure (EXAFS) spectra of Ni

207 adsorbed Hem and Goe standards were quantitatively fit using SixPack (Webb, 2005) using

208 backscattering phase and amplitude functions generated in FEFF 9.6. (Rehr et al., 2010) from the

209 crystal structure of trevorite $\left(\mathrm{NiFe}_{2} \mathrm{O}_{4}\right)$ (Hill et al., 1979) and sarcopside $\left[\left(\mathrm{Ni}_{0.8}{ }_{9} \mathrm{Fe}_{2.11}\right) \mathrm{P}_{2} \mathrm{O}_{8}\right]$

210 (Ericsson and Nord, 1984). Nonlinear least-squares fits were obtained by refining coordination

211 number $(\mathrm{N})$, interatomic distance $(\mathrm{R})$, and $\sigma^{2}$ (a Debye-Waller type factor) (Table EA1). The

212 EXAFS spectra were fit in R-space from 1-4.2 $\AA$ for Ni adsorbed onto goethite and 1-5 $\AA$ for $\mathrm{Ni}$

213 adsorbed onto hematite. $\mathrm{S}_{0}^{2}$, the amplitude reduction factor, was fixed to 0.9 (Frierdich et al.,

214 2011). The $\sigma^{2}$ values were determined using a preliminary fit, and were kept constant for each

215 mineral set (e.g., $\sigma^{2}$ of Ni-Fe1 for Hem and Goe is 0.01 and 0.004 , respectively; $\sigma^{2}$ of Ni-Fe2 for

216 Hem and Goe is 0.009 and 0.008 , respectively) to better compare fits between different

217 conditions and oxoanions.

219 3. RESULTS

\section{$220 \quad 3.1$ Properties of Minerals and Materials}

221 The minerals prepared and used in these experiments have similar properties as those 
222 reported in previous studies (Frierdich et al., 2011; Hinkle et al., 2015). BET surface areas for

223 Hem, Goe, NiHem and NiGoe are 30.1, 42.0, 12.0, and $21.7 \mathrm{~m}^{2} \mathrm{~g}^{-1}$, respectively. The Ni content

224 of NiHem and NiGoe are 1.9 and $1.4 \mathrm{~mol} \%$, respectively. The fractional dissolution of Ni and

225 Fe from NiHem and NiGoe is near congruent (Fig. EA1), in agreement with prior studies of Ni

226 substitution in Fe oxides (Sidhu et al., 1978; Lim-Nunez and Gilkes, 1985; Wells et al., 2001;

227 Frierdich and Catalano, 2012). Ni EXAFS spectral fits of the NiHem and NiGoe materials (not

228 shown) are consistent with EXAFS spectra from previous studies, and are described in detail

229 therein (Singh et al., 2002; Frierdich et al., 2011).

$231 \quad 3.2$ Sulfate and Phosphate Coadsorption with Ni

232 The macroscopic adsorption of Ni onto both Hem and Goe in the presence and absence of 233 phosphate or sulfate are well described by Langmuir isotherms (Fig. 1, Table 1). Consistent with 234 previous research (Arai, 2008), Hem shows a greater affinity for Ni than Goe. The presence of $2350.1 \mathrm{mM}$ sulfate has little effect on $\mathrm{Ni}$ adsorption onto Goe, but slightly enhances Ni adsorption 236 onto Hem. The addition of $0.1 \mathrm{mM}$ phosphate, however, increases Ni adsorption by $\sim 165 \%$ for 237 both the Goe and Hem systems. Ni enhances both phosphate and sulfate adsorption onto Hem to 238 a greater degree than onto Goe (Figs. EA2-3). Phosphate adsorption increases linearly with 239 increasing Ni adsorption $\left(\mathrm{R}^{2}>0.8\right)$ (Fig. EA2B), but there is no clear trend for sulfate adsorption 240 (Fig. EA3B).

241 The EXAFS spectra of Ni adsorbed onto Hem and Goe in the presence of sulfate or 242 phosphate show little variation with oxoanion or mineral concentration and are well reproduced 243 by structural model fits (Fig. 2). The local coordination environment of Ni adsorbed to Goe and 244 Hem, with the exception of $1 \mathrm{~g} \mathrm{~L}^{-1}$ Hem reacted with phosphate, are in agreement with the 
245 observations of Frierdich et al. (2011) and Arai (2008) for oxoanion-free systems. This indicates

246 that sulfate has little effect on Ni adsorption mechanisms onto Fe(III) oxides. Phosphate also has

247 no observed effect on $\mathrm{Ni}$ adsorption mechanisms on goethite or, at high mineral concentrations

248 (4 $\mathrm{g} \mathrm{L}^{-1}$, used for the $\mathrm{Ni}$ incorporation experiments), on hematite. However, at low Hem

249 concentration ( $1 \mathrm{~g} \mathrm{~L}^{-1}$, used for the Ni release experiments), Ni coordination changes, suggesting

250 the presence of a Ni- $\mathrm{PO}_{4}$ ternary complexes. This is supported by the need to include a $\mathrm{P}$

251 neighbor at $\sim 3.8 \AA$ to reproduce the EXAFS spectrum of this sample (Table EA1). In addition,

252 the corner-sharing Ni complex (interatomic Ni-Fe distance of $\sim 4.10 \AA$ ) does not appear due to a

253 low availability of surface sites. These large effects on $\mathrm{Ni}$ adsorption in the presence of

254 phosphate indicate that Ni-phosphate ternary complexes form, while the effect of sulfate is less

255 substantial, suggesting that Ni-sulfate interactions may be dominated by electrostatic

256 interactions.

\section{$258 \quad$ 3.3 Effect of Sulfate and Phosphate on Ni Release}

NiHem and NiGoe were reacted in the presence and absence of sulfate, phosphate, and

$260 \mathrm{Fe}(\mathrm{II})$ to investigate how oxoanions alter Ni release to solution. In the absence of aqueous $\mathrm{Fe}$ (II)

261 and oxoanions, 0.8 and $0.7 \mu \mathrm{M} \mathrm{Ni}$ is released from NiHem and NiGoe, respectively, to solution

262 over 14 days, corresponding to 0.32 and $0.44 \%$ of the total incorporated Ni being released (Fig.

263 3). Sulfate does not affect Ni release from either mineral in the Fe(II)-free system. The presence

264 of phosphate, however, suppresses Ni release from NiGoe to $0.31 \mu \mathrm{M} \mathrm{Ni}$ and inhibits Ni release

265 from NiHem, with the amount of Ni released below the detection limit $(0.1 \mu \mathrm{M})$.

267 oxides (Frierdich et al., 2011; Frierdich and Catalano, 2012) due to Fe(II)-Fe(III) ET-AE 
reactions increasing the rate of iron oxide recrystallization (Pedersen et al., 2005; Handler et al.,

269 2009; Latta et al., 2012b; Gorski et al., 2012; Frierdich et al., 2014). The addition of oxoanions

270 does not appear to alter the rate of Ni release from Fe(III) oxides, but the overall amount of Ni

271 released is substantially suppressed by phosphate. Fe(II)-catalyzed Ni release from NiHem and

272 NiGoe in the presence and absence of oxoanions is consistent with a second-order rate reaction,

273 in agreement with past research of oxoanion-free systems (Frierdich and Catalano, 2012). The

274 second-order rate reaction describing the Ni release data in the current paper was confirmed

275 following the integral method (Brantley and Conrad, 2008). The kinetic fit parameters (Table 2)

276 show that the overall amount of $\mathrm{Ni}$ released is less for NiHem than for NiGoe in the absence of

277 oxoanions (with 1.3\% and 9\% of substituted Ni released, respectively), consistent with past

278 research (Frierdich et al., 2011; Frierdich and Catalano, 2012). The addition of $0.1 \mathrm{mM}$ sulfate

279 has no effect on Ni release from NiHem and NiGoe, with the fit results within error of those for

280 the oxoanion-free system. Phosphate suppresses the total Ni released from NiHem and NiGoe to

281 just $0.64 \%$ and $1.6 \%$, respectively, meaning that an additional $0.66 \%$ and $7.4 \%$ of the

282 preincorporated Ni remains associated with the solid phase relative to the oxoanion-free

283 experiments.

284 To investigate the origin of the increase in solid-associated Ni upon phosphate addition

285 during these Ni release experiment, the relative amounts of incorporated and adsorbed Ni were

286 determined with XANES spectroscopy. The fraction of Ni associated with the solid that remains

287 incorporated at the end of the Ni release experiments was calculated by least-squares linear

288 combination fitting (LCF) of the XANES data, using the Ni substituted Fe(III) oxides and Ni

289 adsorbed onto Fe (III) oxides as end-member standards. The LCF results (Fig. 4, Table 2) show

290 that there is no change in the fraction of $\mathrm{Ni}$ incorporated, when in the absence or presence of 
291 oxoanions, for either the NiHem or NiGoe systems, with 1.00 and 0.98 , respectively, of

292 solid-associated Ni remaining incorporated at the end of the release experiments. These results

293 show that $\mathrm{Ni}$ is not accumulating as an adsorbed layer during Ni release; any Ni that readsorbs to

294 the surface is reincorporated during Fe(II)-catalyzed Fe(III) oxide recrystallization. Thus, these

295 results show that the decrease in macroscopic Ni release from Goe with phosphate cannot solely

296 be due to enhanced readsorption, because that scenario requires $7.4 \%$ of the solid-associated $\mathrm{Ni}$

297 to be adsorbed, well in excess of the LCF uncertainty ( $\pm 2 \%$ ). In the hematite system, the LCF

298 uncertainty is greater than the increase in Ni adsorption needed to explain the decrease in

299 macroscopic Ni release from NiHem with phosphate. However, Ni adsorption onto both Hem

300 and Goe increases substantially upon phosphate addition and it is thus unlikely that buildup of

301 adsorbed Ni during Ni release is an important process for Hem but is irrelevant in the Goe

302 system.

304 3.4 Effect of Sulfate and Phosphate on Ni Incorporation

305 XAFS spectroscopy was also used to assess the effect of sulfate and phosphate on the 306 reverse process, $\mathrm{Fe}(\mathrm{II})$-catalyzed $\mathrm{Ni}$ incorporation into pure Hem and Goe (Fig. 5). The presence

307 of three isosbestic points when comparing the XANES spectra of the experimental samples and

308 the adsorbed Ni and Ni substituted Fe(III) oxide standards (Fig. EA4) suggest that the samples

309 contain mixtures of adsorbed and incorporated $\mathrm{Ni}$. This is consistent with previous findings of

$310 \mathrm{Fe}(\mathrm{II})$-catalyzed Ni incorporation into Hem and Goe (Frierdich et al., 2011). Fitting of the

311 experimental XANES spectra (Table 3) quantified the fraction of solid-associated Ni that is

312 incorporated versus adsorbed. These fitting results were combined with the total concentration of

313 Ni associated with the solid, obtained from the filtrate ICP-OES data, to calculate by mass 
314 balance the concentration of incorporated and adsorbed $\mathrm{Ni}$ (Table 3). The uncertainties in the

315 calculated incorporated and adsorbed $\mathrm{Ni}$ concentrations were obtained using both the uncertainty

316 in the triplicate ICP-OES measurements and the uncertainty in the LCF calculations. In the

317 absence of $\mathrm{Fe}(\mathrm{II}), \sim 85 \%$ of the initial Ni reacted with Hem and Goe is associated with the solid

318 phase at the end of the 30 day reaction. Of that solid-associated $\mathrm{Ni}, 1 \pm 4 \mu \mathrm{M}$ and $27 \pm 3 \mu \mathrm{M} \mathrm{Ni}$

319 is incorporated into Hem and Goe, respectively, consistent with past studies of Ni incorporation

320 into goethite in natural and aged synthetic samples (Manceau et al., 2000; Singh et al., 2002;

321 Carvalho-e-Silva et al., 2003). The addition of sulfate increases overall Ni incorporation into

322 Hem and Goe. In contrast, addition of phosphate suppresses $\mathrm{Ni}$ incorporation into Goe; Ni

323 incorporation into Hem is within error of zero regardless of the amount of phosphate present.

324 These results indicate that Ni incorporation into Fe(III) oxide minerals in the absence of Fe(II) is 325 affected by oxoanions.

326 The addition of Fe(II) substantially increases Ni incorporation into Goe, but suppresses

327 the overall amount of sorbed $\mathrm{Ni}$ in the Goe system, indicative of competitive adsorption between

328 aqueous $\mathrm{Fe}(\mathrm{II})$ and $\mathrm{Ni}$ (Table 3). Aqueous $\mathrm{Fe}(\mathrm{II})$ does not alter the total amount of sorbed Ni in

329 the Hem system, but does increase Ni incorporation. The lack of competitive adsorption effects

330 between $\mathrm{Ni}$ and $\mathrm{Fe}(\mathrm{II})$ on Hem suggests that the Ni binding affinity for Hem is greater than for

331 Goe, consistent with the adsorption isotherm measurements (Fig. 1) and past observations (Arai,

332 2008). In the presence of $1.0 \mathrm{mM} \mathrm{Fe}(\mathrm{II})$, equivalent $\mathrm{Ni}$ concentrations incorporate into the solid

333 phases and adsorb to the mineral surfaces, with $\sim 92 \pm 6 \mu \mathrm{M}$ and $52 \pm 3 \mu \mathrm{M}$ Ni both incorporated

334 and adsorbed in the Hem and Goe systems, respectively. Addition of $0.5 \mathrm{mM} \mathrm{Fe}$ (II) (used in the

335 phosphate experiments to prevent vivianite precipitation) results in less Ni incorporation, with

$3360.67 \pm 4 \mu \mathrm{M}$ and $0.49 \pm 3 \mu \mathrm{M} \mathrm{Ni}$ incorporated into Hem and Goe, respectively. 
338 recrystallization. The co-addition of $0.1 \mathrm{mM}$ sulfate and $1.0 \mathrm{mM} \mathrm{Fe}(\mathrm{II})$ to a Goe suspension

339 increases the overall concentration of $\mathrm{Ni}$ associated with the solid as a result of increased $\mathrm{Ni}$

340 incorporation (Table 3 ). The addition of $1.0 \mathrm{mM}$ sulfate to this system slightly reduces $\mathrm{Ni}$

341 incorporation relative to the $0.1 \mathrm{mM}$ sulfate experiment. In both Goe experiments, Ni adsorption

342 remains statistically invariant. In contrast, $0.1 \mathrm{mM}$ sulfate has no effect on Ni incorporation into

343 or adsorption onto Hem in the presence of $1.0 \mathrm{mM} \mathrm{Fe}(\mathrm{II})$, while $1.0 \mathrm{mM}$ sulfate causes a

344 reduction in Ni incorporation but an increase in Ni adsorption.

345 Phosphate also affects Ni partitioning during Fe(II)-catalyzed recrystallization of Hem

346 and Goe, but these effects are distinct from the changes caused by sulfate. The addition of 0.5

$347 \mathrm{mM}$ phosphate and Fe(II) substantially increases Ni adsorption onto the Goe surface (Table 3).

348 In addition, phosphate enhances the amount of Ni incorporated into Goe (Table 3). In the Hem

349 system, however, the addition of phosphate substantially decreases Ni incorporation, with 0.5

$350 \mathrm{mM}$ phosphate causing complete inhibition. The effects of phosphate are not the result of

351 precipitation of phosphate-bearing solids. The Ni K-edge XANES spectra (Fig. 5) lack a

352 shoulder at $\sim 8334 \mathrm{eV}$ that is present in the spectrum of Ni-phosphate minerals (e.g., arupite,

$\left.353 \mathrm{Ni}_{3}\left(\mathrm{PO}_{4}\right)_{2} \bullet 8 \mathrm{H}_{2} \mathrm{O}\right)($ Singh, 2006). Prior work shows that vivianite will not form under the

354 conditions studied (Hinkle et al., 2015), and the spectrum of Ni substituting in vivianite is also

355 expected to display a shoulder given the similarity of the Ni XANES spectrum of arupite (Singh,

356 2006) and the Fe XANES spectrum of vivianite (Cosmidis et al., 2014).

359 4.1 Oxoanion- and Mineral-Specific Effects on Ni Repartitioning 


\subsubsection{Mechanisms of Oxoanion Effects on Ni Repartitioning}

Phosphate in general has a substantially greater effect on Ni repartitioning during Fe(II)-

362 catalyzed recrystallization than sulfate. In the hematite system, phosphate strongly suppresses $\mathrm{Ni}$

363 incorporation into and release from the mineral while sulfate only slightly alters the behavior

364 seen in oxoanion-free systems. Fe(II)-catalyzed Ni repartitioning in $\mathrm{Fe}(\mathrm{III})$ oxides is

365 fundamentally controlled by adsorption reactions and the effects of oxoanions on this process are

366 likely the result of molecular interactions of adsorbates on mineral surfaces. Both phosphate and

367 sulfate form surface complexes with bidentate symmetry on hematite (Paul et al., 2005; Elzinga

368 and Kretzschmar, 2013; Jubb et al., 2013; Hinkle et al., 2015). While phosphate clearly forms

369 bidentate binuclear surface complexes, the nature of sulfate surface complexes is unclear

370 regarding whether these are inner- or outer-sphere (or a mixture). The formation of bidentate

371 binuclear surface complexes likely suppresses hematite dissolution and growth (Bondietti et al.,

372 1993; Stumm, 1997). Therefore phosphate surface complexes may effectively prevent hematite

373 recrystallization, inhibiting Fe(II)-catalyzed Ni repartitioning. Adsorbate inhibition of

374 recrystallization, however, cannot be a dominant process in the sulfate-hematite system because

$375 \mathrm{Ni}$ incorporation into hematite in the absence of Fe(II) actually increases upon addition of

376 sulfate. The subsequent decrease in $\mathrm{Ni}$ incorporation into hematite when $1.0 \mathrm{mM}$ sulfate and 1.0

$377 \mathrm{mM} \mathrm{Fe}(\mathrm{II})$ are added thus suggests that $\mathrm{Fe}(\mathrm{II})$-sulfate-hematite interactions, which include the

378 formation of $\mathrm{Fe}(\mathrm{II})$-sulfate ternary surface complexes (Hinkle et al., 2015), are likely responsible

379 for the observed effect.

380 Oxoanion-Fe(II) interactions are also important in controlling Ni repartitioning behavior

381 in the phosphate-goethite system, as phosphate suppresses Ni incorporation in the absence of

$382 \mathrm{Fe}(\mathrm{II})$ but enhances $\mathrm{Ni}$ incorporation in the presence of $\mathrm{Fe}(\mathrm{II})$ (Table 3). The Fe(II)-free 
383 experiments are in agreement with previous research finding that phosphate suppresses goethite 384 dissolution in the absence of Fe(II) (Stumm, 1993; Biber et al., 1994). The effect of phosphate in 385 the Fe(II) system is consistent with a recent isotope exchange study demonstrating that 386 phosphate enhances the rate and extent of $\mathrm{Fe}$ atom exchange between goethite and aqueous 387 Fe(II) (Latta et al., 2012a). It should be noted that the present study was conducted under 388 different $\mathrm{Fe}(\mathrm{II})$ and phosphate surface loadings, therefore a direct comparison with the results 389 from Latta et al. (2012a) is not possible. If phosphate does enhance Fe(II)-catalyzed goethite 390 recrystallization under the conditions used in the current study, then macroscopic Ni release 391 should also increase. In phosphate-free Fe(II)-catalyzed Ni release experiments, most (>85\%) of 392 the Ni released is actually reincorporated into goethite rather than remaining in the aqueous 393 phase (Frierdich et al., 2012). Because phosphate substantially increases Ni adsorption (Fig. 1;

394 Table 1), a necessary intermediate step during incorporation, phosphate likely increases Ni 395 reincorporation during Fe(II)-catalyzed goethite recrystallization, thereby decreasing 396 macroscopic Ni release. Phosphate may thus enhance Ni incorporation into goethite in both the $397 \mathrm{Fe}(\mathrm{II})$-catalyzed Ni release and Ni incorporation experiments by increasing Fe(II)-catalyzed 398 goethite recrystallization (Latta et al., 2012a) through increased Fe(II) surface coverage (Hinkle 399 et al., 2015), and by substantially increasing $\mathrm{Ni}$ (re)adsorption to (and therefore $\mathrm{Ni}$ 400 (re)incorporation into) the surface.

401 Although sulfate also enhances Fe(II)-catalyzed Ni incorporation into goethite, its effect 402 on Ni release differs substantially from the phosphate-goethite system. Interestingly, sulfate 403 exhibits different effects on total macroscopic Ni sorption onto goethite in the absence (Fig. 1;

404 Table 1) and presence of Fe(II) (Table 3). These results suggest that sulfate moderates Ni-Fe(II) 405 competitive adsorption on goethite, preferentially increasing overall Ni sorption without 
406 affecting Fe(II) surface coverage. By lessening Ni-Fe(II) competitive adsorption effects on

407 goethite, sulfate allows more Ni to adsorb to the surface and thus become incorporated into

408 goethite. Competitive adsorption of $\mathrm{Ni}$ and $\mathrm{Fe}(\mathrm{II})$ is likely less substantial in the Ni release

409 experiments because of the lower Ni concentrations. As a result, sulfate does not appreciably

410 affect Ni release.

411

412 4.1.2 Mineral-Specific Effects

413 Although the mechanisms through which each oxoanion alters Ni cycling in Fe(III)

414 oxides differ depending on the specific oxoanion-mineral system, goethite- and hematite-specific

415 effects are observed, suggesting these minerals exhibit distinct behaviors during biogeochemical

416 Fe cycling in the presence of oxoanions. Both oxoanions decrease Fe(II)-catalyzed incorporation

417 of Ni into hematite and phosphate suppresses Ni release from this mineral. These observations

418 suggest that Fe(II)-catalyzed Ni cycling through hematite is inhibited by oxoanions because such

419 species alter Fe(II) adsorption mechanisms and hematite recrystallization. Conversely, this

420 research indicates that phosphate and sulfate do not prevent Ni repartitioning during Fe(II)-

421 catalyzed goethite recrystallization, suggesting that these oxoanions do not interfere with Fe(II)-

422 Fe(III) ET-AE processes. Instead, phosphate and sulfate largely affect Ni cycling through

423 goethite by increasing the extent of $\mathrm{Ni}$ adsorption. These results suggest that the mineral identity

424 is an important controlling factor in predicting how oxoanions may alter processes associated

425 with $\mathrm{Fe}(\mathrm{II})-\mathrm{Fe}(\mathrm{III}) \mathrm{ET}-\mathrm{AE}$ reactions.

426

427 4.2 Environmental and Geological Implications of Trace Element Fate

428 This study demonstrates that oxoanions common to aquatic systems affect trace element 
429 fate at redox interfaces in environmental and geological systems. Because trace metals are often 430 associated with (Singh and Gilkes, 1992; Manceau et al., 2002; Cornell and Schwertmann, 2003)

431 and incorporated into (Singh and Gilkes, 1992; Manceau et al., 2000; Carvalho-e-Silva et al., 432 2003) naturally-occurring iron oxides, micronutrient bioavailability is often limited by the 433 extractability of these trace metals from iron oxides. Phosphate suppresses net Fe(II)-catalyzed

434 Ni release from hematite. Therefore Ni bioavailability in hematite-dominated environments with 435 Fe redox gradients may be lower in systems with substantial phosphate uptake by iron oxides 436 [e.g., hydrothermal vents (Froelich et al., 1982; Berner et al., 1993) and waterlogged subtropical 437 or tropical soils (Parfitt, 1989; Chacon, 2006)]. However, Ni bioavailability in systems with large 438 reactive goethite fractions and coexisting aqueous $\mathrm{Fe}(\mathrm{II})$ [e.g., soils, lacustrine and marine 439 sediments (Drodt et al., 1997; Cornell and Schwertmann, 2003; van der Zee et al., 2003)] will 440 likely not be affected by oxoanion concentration, as phosphate and sulfate do not impede $\mathrm{Ni}$ 441 cycling through goethite.

442 Heavy metal contamination of soils and aquatic systems is often mediated by iron or 443 manganese oxide adsorption processes (Mench et al., 1994; Fuller and Harvey, 2000; Sowder et 444 al., 2003; Isaure et al., 2005; Waychunas et al., 2005; Tankere-Muller et al., 2007). Phosphate 445 exerts a large effect on macroscopic $\mathrm{Ni}$ adsorption onto both hematite and goethite, resulting in 446 decreased Ni concentrations in the aqueous phase. Thus, phosphate may exert a substantial 447 control on Ni retention in riparian soils by increasing Ni adsorption to iron oxide minerals, an 448 important control on the contamination of nearby soils (Sowder et al., 2003). Further entrapment 449 of Ni by incorporation into hematite may, however, be prevented by phosphate and sulfate in 450 these systems. Conversely, enhanced Ni incorporation into goethite by sulfate and phosphate 451 does not translate into increased Ni entrapment, as Ni cycling is not obstructed by either 
oxoanion.

453 This research shows that Ni cycling in iron oxides is altered by phosphate and sulfate

454 differently depending on both the mineral identity and the concentration and identity of the

455 oxoanions, which may have important ramifications for the preservation of $\mathrm{Ni}$ in the rock record.

456 For example, these results indicate that the amount of $\mathrm{Ni}$ incorporated into banded iron

457 formations (BIFs), which formed in oceans containing dissolved Fe(II) (Holland, 1973; Holland,

458 1984; Derry and Jacobsen, 1990; Holland, 2006), was likely dependent on a number of factors,

459 including the oceanic sulfate and phosphate concentrations. The results of this research also

460 indicate that the retention of Ni may have been affected by the identity of minerals formed

461 through phase transformations of initial iron (oxyhydr)oxide precipitates during BIF deposition,

462 burial, and lithification. Phosphate could further affect the amount of Ni incorporated into BIFs

463 during lithification by preferentially enhancing Ni adsorption onto iron oxides. Phosphate and

464 sulfate may also alter trace element partitioning during diagenesis and fluid flow through

465 sediments. Thus, the relationship between Ni concentrations in BIFs and ancient seawater is

466 almost certainly not straightforward, as has been assumed in prior studies, e.g., (Konhauser et al.,

467 2009). Instead, recorded Ni concentrations will have a highly non-linear dependence on fluid

468 composition, mineral properties, and depositional and post-depositional processes. The present

469 work clearly shows that species incompatible with Fe(III) oxide structures, such as phosphate

470 and sulfate, still have substantial impacts on the partitioning of structurally compatible metals in

471 a variety of environments, potentially altering micronutrient bioavailability, contaminant

472 sequestration, and geochemical proxies.

\section{5. ACKNOWLEDGMENTS}


This research was supported by the National Science Foundation (NSF), Division of

476 Earth Sciences, Geobiology and Low-Temperature Geochemistry Program through Grant No.

477 EAR-1056480. ICP-OES analyses were conducted at the Nano Research Facility at Washington

478 University, supported by the NSF through award no. ECS-0335765. Use of the Bruker D8

479 Advance XRD at Washington University in St. Louis is supported by the National Science

480 Foundation through award no. EAR-1161543. XAFS spectra were collected at beamlines

481 9-BM-C and 12-BM-B at the Advanced Photon Source, an Office of Science User Facility

482 operated for the U.S. Department of Energy (DOE) Office of Science by Argonne National

483 Laboratory, which is supported by the U.S. DOE under Contract No. DE-AC02-06CH11357.

484 The authors thank Jennifer Houghton and Sanmathi Chavalmane for their help with collecting IC

485 and ICP-OES analyses, respectively.

487 ASSOCIATED CONTENT

488 Electronic Annex. Additional information regarding second order kinetic fits of the macroscopic

489 Ni release data, figures of fractional dissolution of Ni substituted Fe(III) oxides and macroscopic

490 oxoanion adsorption, and a table of XAFS fitting results for Ni adsorbed onto Fe(III) oxides.

\section{REFERENCES}

494 Arai Y. (2008) Spectroscopic evidence for Ni(II) surface speciation at the iron oxyhydroxides-water interface. Environ. Sci. Technol. 42, 1151-1156. major ion seawater. Geochim. Cosmochim. Acta 40, 1253-1265.

Beard B. L., Handler R. M., Scherer M. M., Wu L., Czaja A. D., Heimann A. and Johnson C. M. (2010) Iron isotope fractionation between aqueous ferrous iron and goethite. Earth

500 Planet. Sci. Lett. 295, 241-250. 
Benjamin M. M. and Bloom N. S. (1981) Effects of strong binding of anionic adsorbates on adsorption of trace metals on amorphous iron oxyhydroxide. In Adsorption From Aqueous Solutions (ed. P.H. Tewari), Plenum Press, New York. pp. 41-60.

Berner R. A., Ruttenberg K. C., Ingall E. D. and Rao, J. L. (1993) The nature of phosphorus burial in modern marine sediments. In Interactions of $C, N, P$, and $S$ Biogeochemical Cycles and Global Change (eds. R. Wollast, F.T. Mackenzie and L. Chou), SpringerVerlag, Berlin. pp. 365-378.

Biber M. V., dos Santos Afonso M. and Stumm W. (1994) The coordination chemistry of weathering: IV. Inhibition of the dissolution of oxide minerals. Geochim. Cosmochim. Acta 58, 1999-2010.

Bondietti G., Sinniger J. and Stumm W. (1993) The reactivity of Fe(III) (hydr)oxides: effects of ligands in inhibiting the dissolution. Colloids Surf., A 79, 157-167.

Borch T., Masue, Y., Kukkadapu R. K. and Fendorf S. (2007) Phosphate imposed limitations on biological reduction and alteration of ferrihydrite. Environ. Sci. Technol. 41, 166-172.

Brantley S. L. and Conrad C. F. (2008) Analysis of Rates of Geochemical Reactions, In Kinetics of Water-Rock Interaction (eds. J.D. Kubicki and A.F. White). Springer, New York. pp. $1-37$.

Brown G. E., Henrich V., Casey W., Clark D. and Eggleston C. M. (1999) Metal oxide surfaces and their interactions with aqueous solutions and microbial organisms. Chem. Rev. 99, $77-174$.

Brown G. E. and Parks G. A. (2001) Sorption of trace elements on mineral surfaces: Modern perspectives from spectroscopic studies, and comments on sorption in the marine environment. Int. Geol. Rev. 43, 963-1073.

Carvalho-e-Silva M. L., Ramos A. Y., Tolentino H. C. N., Enzweiler J., Netto S. M. and Alves M. D. C. M. (2003) Incorporation of Ni into natural goethite: An investigation by X-ray absorption spectroscopy. Am. Mineral. 88, 876-882.

Catalano J. G., Fenter P., Park C., Zhang Z. and Rosso K. M. (2010) Structure and oxidation state of hematite surfaces reacted with aqueous $\mathrm{Fe}(\mathrm{II})$ at acidic and neutral $\mathrm{pH}$. Geochim. Cosmochim. Acta 74, 1498-1512.

Chacon N., Silver W. L., Dubinsky E. A. and Cusak D. F. (2006) Iron reduction and soil phosphorus solubilization in humid tropical forests soils: The roles of labile carbon pools and an electron shuttle compound. Biogeochemistry 78, 67-84.

Collins C. R., Ragnarsdottir K. V. and Sherman D. M. (1999) Effect of inorganic and organic ligands on the mechanism of cadmium sorption to goethite. Geochim. Cosmochim. Acta 63, 2989-3002.

Cosmidis J., Benzerara K., Morin G., Busigny V., Lebeau O., Jézéquel D., Noël V., Dublet G. 
and Othmane G. (2014) Biomineralization of iron-phosphates in the water column of Lake Pavin (Massif Central, France). Geochim. Cosmochim. Acta 126, 78-96.

Cornell R. M. and Schwertmann U. (2003) The iron oxides: Structure, properties, reactions, occurrences and uses. WILEY-VCH Verlag GmbH \& Co. KGaA, Weinheim.

Crosby H. A., Johnson C. M., Roden E. E. and Beard B. L. (2005) Coupled Fe(II)-Fe(III) electron and atom exchange as a mechanism for Fe isotope fractionation during dissimilatory iron oxide reduction. Environ. Sci. Technol. 39, 6698-6704.

Derry L. A. and Jacobsen S. B. (1990) The chemical evolution of Precambrian seawater: Evidence from REEs in banded iron formations. Geochim. Cosmochim. Acta 54, $2965-$ 2977.

Diaz-Barrientos E., Madrid L., Contreras M. C. and Morillo E. (1990) Simultaneous adsorption of zinc and phosphate on synthetic lepidocrocite. Aust. J. Soil Res. 28, 549-557.

Drodt M., Trautwein A. X., König I., Suess E. and Koch C. B. (1997) Mössbauer spectroscopic studies on the iron forms of deep-sea sediments. Phys. Chem. Miner. 24, 281-293.

Eggleston C. M., Hug S., Stumm W., Sulzberger B. and Dos Santos Afonso M. (1998) Surface complexation of sulfate by hematite surfaces: FTIR and STM observations. Geochim. Cosmochim. Acta 62, 585-593.

Elzinga E. J. and Kretzschmar R. (2013) In situ ATR-FTIR spectroscopic analysis of the coadsorption of orthophosphate and Cd(II) onto hematite. Geochim. Cosmochim. Acta 117, 53-64.

Ericsson T. and Nord A. G. (1984) Strong cation ordering in olivine-related (Ni, Fe)-sarcopsides: A combined Mössbauer, X-ray and neutron diffraction study. Am. Mineral. 69, 889-895.

Frierdich A. J., Beard B. L., Reddy T. R., Scherer M. M. and Johnson C. M. (2014) Iron isotope fractionation between aqueous Fe(II) and goethite revisited: New insights based on a multi-direction approach to equilibrium and isotopic exchange rate modification. Geochim. Cosmochim. Acta 139, 383-398.

Frierdich A. J. and Catalano J. G. (2012) Controls on Fe(II)-activated trace element release from goethite and hematite. Environ. Sci. Technol. 46, 1519-1526.

Frierdich A. J., Luo Y. and Catalano J. G. (2011) Trace element cycling through iron oxide minerals during redox-driven dynamic recrystallization. Geol. 39, 1083-1086.

Frierdich A. J., Scherer M. M., Bachman J. E., Engelhard M. H., Rapponotti B. W. and Catalano J. G. (2012) Inhibition of trace element release during Fe(II)-activated recrystallization of Al-, Cr-, and Sn-substituted goethite and hematite. Environ. Sci. Technol. 46, 1003110039.

571 Froelich P. N., Bender M. L. and Luedtke N. A. (1982) The marine phosphorus cycle. Am. J. Sci. 
573

Fuller C. C. and Harvey J. W. (2000) Reactive uptake of trace metals in the hyporheic zone of a mining-contaminated stream, Pinal Creek, Arizona. Environ. Sci. Technol. 34, 11501155.

Gorski C. A., Handler R. M., Beard B. L., Pasakarnis T., Johnson C. M. and Scherer M. M. (2012) $\mathrm{Fe}$ atom exchange between aqueous $\mathrm{Fe}^{2+}$ and magnetite. Environ. Sci. Technol. 46, $12399-12407$.

Gorski C. A. and Scherer M. M. (2011) Fe2+ sorption at the Fe oxide-water interface: A revised conceptual framework. Aquatic Redox Chemistry 1071, 477-517.

Handler R. M., Beard B. L., Johnson C. M. and Scherer M. M. (2009) Atom exchange between aqueous Fe(II) and goethite: an Fe isotope tracer study. Environ. Sci. Technol. 43, 11021107.

Handler R. M., Frierdich A. J., Johnson C. M., Rosso K. M., Beard B. L., Wang C., Latta D. E., Neumann A., Pasakarnis T. and Premaratne W. (2014) Fe (II)-catalyzed recrystallization of goethite revisited. Environ. Sci. Technol. 48, 11302-11311.

Hansel C. M., Benner S. G. and Fendorf S. (2005) Competing Fe(II)-induced mineralization pathways of ferrihydrite. Environ. Sci. Technol. 39, 7147-7153.

Hansel C. M., Benner S. G., Neiss J., Dohnalkova A., Kukkadapu R. K. and Fendorf S. (2003) Secondary mineralization pathways induced by dissimilatory iron reduction of ferrihydrite under advective flow. Geochim. Cosmochim. Acta 67, 2977-2992.

Hansel C. M., Benner S. G., Nico P. and Fendorf S. (2004) Structural constrains of ferric (hydr)oxides on dissimilatory iron reduction and the fate of Fe(II). Geochim. Cosmochim. Acta 68, 3217-3229.

Hill R. J., Craig, J. R. and Gibbs, G. V. (1979) Systematics of the spinel structure type. Phys. Chem. Miner. 4, 317-339.

Hinkle M. A. G., Wang Z., Giammar D. E. and Catalano J. G. (2015) Interaction of Fe(II) with phosphate and sulfate on iron oxide surfaces. Geochim. Cosmochim. Acta 158, 130-146..

Hoins U. (1993) Ligand effect on the adsorption of heavy metals: The sulfate-cadmium-goethite case. Water, Air, Soil Pollut. 68, 241-255.

Holland H. D. (1973) The Oceans; A Possible Source of Iron in Iron-Formations. Econ. Geol. 68, 1169-1172.

Holland H. D. (1984) The chemical evolution of the atmosphere and oceans. Princeton University Press, New Jersey.

Holland H. D. (2006) The oxygenation of the atmosphere and oceans. Philos. T. Roy. Soc. B. 
361, 903-915.

607

608

609

610

611

612

613

614

615

616

617

618

619

620

621

622

623

624

625

626

627

628

629

630

631

632

633

634

635

636

637

638

639

640

Isaure M. -P., Manceau A., Geoffroy N., Laboudigue A., Tamura N. and Marcus M. A. (2005) Zinc mobility and speciation in soil covered by contaminated dredged sediment using micrometer-scale and bulk-averaging X-ray fluorescence, absorption and diffraction techniques. Geochim. Cosmochim. Acta 69, 1173-1198.

Jeon B. H., Dempsey B. A., Burgos W. D. and Royer R. A. (2001) Reactions of ferrous iron with hematite. Colloids Surf., A 191, 41-55.

Juang R. and Wu W. (2002) Adsorption of sulfate and copper(II) on goethite in relation to the changes of zeta potentials. J. Colloid Interface Sci. 249, 22-29.

Jubb A. M., Verreault D., Posner R., Criscenti L. J., Katz L. E. and Allen H. C. (2013) Sulfate adsorption at the buried hematite/solution interface investigated using total internal reflection (TIR)-Raman spectroscopy. J. Colloid Interface Sci. 400, 140-146.

Konhauser K., Pecoits E., Lalonde S. V., Papineau D., Nisbet E. G., Barley M. E., Arndt N. T., Zahnle K. and Kamber B. S. (2009) Oceanic nickel depletion and a methanogen famine before the Great Oxidation Event. Nature 458, 750-753.

Larese-Casanova P. and Scherer M. M. (2007) Fe(II) sorption on hematite: New insights based on spectroscopic measurements. Environ. Sci. Technol. 41, 471-477.

Latta D. E., Bachman J. E. and Scherer M. M. (2012a) Fe electron transfer and atom exchange in goethite: Influence of Al-substitution and anion sorption. Environ. Sci. Technol. 46, 10614-10623.

Latta D. E., Gorski C. A. and Scherer M. M. (2012b) Influence of $\mathrm{Fe}^{2+}$-catalyzed iron oxide recrystallization on metal cycling. Biochem. Soc. T. 40, 1191-7.

Lim-Nunez R. and Gilkes R. J. (1985) Acid dissolution of synthetic metal-containing goethites and hematites. In Proceedings of the International Clay Conference, pp. 197-204.

Madrid L., Diaz-Barrientos E. and Contreras M. C. (1991) Relationships between zinc and phosphate adsorption on montmorillonite and an iron oxyhydroxide. Aust. J. Soil Res. 29, 239-247.

Majzlan J. and Myneni S. C. B. (2005) Speciation of iron and sulfate in acid waters: Aqueous clusters to mineral precipitates. Environ. Sci. Technol. 39, 188-194.

Manceau A., Schlegel M. L., Musso M., Sole V. A., Gauthier C., Petit P. E. and Trolard F. (2000) Crystal chemistry of trace elements in natural and synthetic goethite. Geochim. Cosmochim. Acta 64, 3643-3661.

Manceau A., Tamura N., Celestre R. S., MacDowell A. A., Geoffroy N., Sposito G. and Padmore H. A. (2002) Molecular-scale speciation of $\mathrm{Zn}$ and $\mathrm{Ni}$ in soil ferromanganese nodules from loess soils of the Mississippi Basin. Environ. Sci. Technol. 37, 75-80. 
Mench M. J., Didier V. L., Loffler M., Gomez A. and Masson P. (1994) A mimicked in situ remediation study of metal-contaminated soils with emphasis on cadmium lead. $J$. Environ. Qual. 23, 58-63.

Newville M. (2001) IFEFFIT: interactive EXAFS analysis and FEFF fitting. J. Synchrotron Radiat. 8, 322-324.

Parfitt R. L., Hume L. J. and Sparling G.P. (1989) Loss of availability of phosphate in New Zealand soils. J. Soil Sci. 40, 371-382.

Paul K. W., Borda M. J., Kubicki J. D. and Sparks D. L. (2005) Effect of dehydration on sulfate coordination and speciation at the Fe-(hydr)oxide-water interface: A Molecular Orbital/Density Functional Theory and Fourier transform infrared spectroscopic investigation. Langmuir 21, 11071-11078.

Pedersen H. D., Postma D., Jakobsen R. and Larsen O. (2005) Fast transformation of iron oxyhydroxides by the catalytic action of aqueous Fe(II). Geochim. Cosmochim. Acta 69, 3967-3977.

Ravel B. and Newville M. (2005) ATHENA, ARTEMIS, HEPHAESTUS: data analysis for Xray absorption spectroscopy using IFEFFIT. J. Synchrotron Radiat. 12, 537-541.

Rehr J. J., Kas J. J., Vila F. D., Prange M. P. and Jorissen K. (2010) Parameter-free calculations of x-ray spectra with FEFF9. Phys. Chem. Chem. Phys. 12, 5503-5513.

Schwertmann U. and Cornell R. M. (2000) Iron oxides in the laboratory: preparation and characterization. Wiley-VCH, Weinheim.

Sidhu P. S., Gilkes R. J. and Posner A. M. (1978) The synthesis and some properties of Co, Ni, $\mathrm{Zn}, \mathrm{Cu}, \mathrm{Mn}$ and $\mathrm{Cd}$ substituted magnetites. J. Inorg. Nucl. Chem. 40, 429-435.

Singh B. and Gilkes R. J. (1992) Properties and distribution of iron oxides and their association with minor elements in the soils of south-western Australia. J. Soil Sci. 43, 77-98.

Singh B., Sherman D. M., Gilkes R. J., Wells M. A. and Mosselmans J. F. W. (2002) Incorporation of $\mathrm{Cr}, \mathrm{Mn}$ and $\mathrm{Ni}$ into goethite $(\alpha-\mathrm{FeOOH})$ : mechanism from extended $\mathrm{X}$ ray absorption fine structure spectroscopy. Clay Miner. 37, 639-649.

Singh V. K. (2006) Bonding parameter, phase parameter and Ni K-edge position studies of some Ni systems. Indian J. Pure Appl. Phys. 44, 20-24.

Sowder A. G., Bertsch P. M. and Morris P. J. (2003) Partitioning and availability of uranium and nickel in contaminated riparian sediments. J. Environ. Qual. 32, 885-898.

Stumm W. (1993) From surface acidity to surface reactivity; inhibition of oxide dissolution. Aquat. Sci. 55, 273-280.

Stumm W. (1997) Reactivity at the mineral-water interface: dissolution and inhibition. Colloids 
Surf., A 120, 143-166.

676

677

678

679

680

681

682

683

684

685

686

687

688

689

690

691

692

693

694

695

696

697

698

699

700

701

702

703

Swedlund P. J., Webster J. G. and Miskelly G. M. (2003) The effect of $\mathrm{SO}_{4}$ on the ferrihydrite adsorption of $\mathrm{Co}, \mathrm{Pb}$ and $\mathrm{Cd}$ : ternary complexes and site heterogeneity. Appl. Geochem. 18, 1671-1689.

Tankere-Muller S., Zhang H., Davison W., Finke N., Larsen O., Stahl H. and Glud R. N. (2007) Fine scale remobilisation of $\mathrm{Fe}, \mathrm{Mn}, \mathrm{Co}, \mathrm{Ni}, \mathrm{Cu}$ and $\mathrm{Cd}$ in contaminated marine sediment. Mar. Chem. 106, 192-207.

van der Zee C., Roberts D. R., Rancourt D. G. and Slomp C. P. (2003) Nanogoethite is the dominant reactive oxyhydroxide phase in lake and marine sediments. Geol. 31, 993-996.

Venema P., Hiemstra T. and van Riemsdijk W. H. (1997) Interaction of Cadmium with Phosphate on Goethite. J. Colloid Interface Sci. 192, 94-103.

Waychunas G. A., Kim C. S. and Banfield J. F. (2005) Nanoparticulate iron oxide minerals in soils and sediments: unique properties and contaminant scavenging mechanisms. $J$. Nanopart. Res. 7, 409-433.

Webb S. M. (2005) SIXPack: A Graphical User Interface for XAS Analysis using IFEFFIT. Physica Scripta T115, 1011-1014.

Wells M. A., Gilkes R. J. and Fitzpatrick R. W. (2001) Properties and acid dissolution of metalsubstituted hematites. Clays Clay Miner. 49, 60-72.

Williams A. G. B. and Scherer M. M. (2004) Spectroscopic evidence for Fe(II)-Fe(III) electron transfer at the iron oxide-water interface. Environ. Sci. Technol. 38, 4782-90.

Wu L., Beard B. L., Roden E. E., Kennedy C. B. and Johnson C. M. (2010) Stable Fe isotope fractionations produced by aqueous Fe(II)-hematite surface interactions. Geochim. Cosmochim. Acta 74, 4249-4265.

Yang L., Steefel C. I., Marcus M. A. and Bargar J. R. (2010) Kinetics of Fe (II)-catalyzed transformation of 6-line ferrihydrite under anaerobic flow conditions. Environ. Sci. Technol. 44, 5469-5475.

Yanina S. V. and Rosso K. M. (2008) Linked reactivity at mineral-water interfaces through bulk crystal conduction. Science 320, 218-22. 


\section{TABLES}

Table 1. Langmuir isotherm parameters determined for $\mathrm{Ni}$ adsorption to goethite and hematite.

\begin{tabular}{lcc}
\hline Sample & $\Gamma_{\max }\left(\mu \mathbf{m o l ~ \mathbf { ~ } ^ { - 1 } )}\right.$ & $\mathbf{K}\left(\mathbf{m L ~} \mathbf{m m o l}^{-\mathbf{1}}\right)$ \\
\hline Hematite & $44 \pm 6$ & $12 \pm 4$ \\
Oxoanion-free & $58 \pm 7$ & $11 \pm 3$ \\
$0.1 \mathrm{mM} \mathrm{SO}_{4}$ & $117 \pm 2$ & $82 \pm 6$ \\
$0.1 \mathrm{mM} \mathrm{PO}_{4}$ & & \\
Goethite & $15 \pm 2$ & $80 \pm 40$ \\
Oxoanion-free & $16 \pm 2$ & $110 \pm 60$ \\
$0.1 \mathrm{mM} \mathrm{SO}_{4}$ & $40 \pm 2$ & $250 \pm 70$ \\
$0.1 \mathrm{mM} \mathrm{PO}_{4}$ &
\end{tabular}

Table 2. Kinetic fit parameters, extent of Ni release, and final solid phase Ni speciation following reaction of $1.0 \mathrm{mM} \mathrm{Fe}(\mathrm{II})$ with Ni-substituted $\mathrm{Fe}(\mathrm{III})$ oxides.

\begin{tabular}{|c|c|c|c|c|}
\hline Sample & $k_{o b s}\left(\mu \mathbf{M ~ d}^{-1}\right)^{a}$ & {$[\mathbf{N i}]_{\mathrm{eq}}(\mu \mathbf{M})^{a}$} & Total Release $(\%)^{b}$ & f(Ni incorporated) \\
\hline \multicolumn{5}{|l|}{ NiHem } \\
\hline Oxoanion-free & $1.3 \pm 0.9$ & $3.2 \pm 0.3$ & $1.3 \pm 0.1$ & $1.000 \pm 0.001$ \\
\hline $0.1 \mathrm{mM} \mathrm{SO}_{4}$ & $0.8 \pm 0.6$ & $3.4 \pm 0.4$ & $1.4 \pm 0.1$ & $1.000 \pm 0.001$ \\
\hline $0.1 \mathrm{mM} \mathrm{PO}_{4}$ & $21 \pm 13$ & $1.6 \pm 0.2$ & $0.64 \pm 0.04$ & $1.00 \pm 0.03$ \\
\hline \multicolumn{5}{|l|}{ NiGoe } \\
\hline Oxoanion-free & $0.03 \pm 0.02$ & $14 \pm 2$ & $9 \pm 1$ & $0.98 \pm 0.02$ \\
\hline $0.1 \mathrm{mM} \mathrm{SO}_{4}$ & $0.04 \pm 0.02$ & $13 \pm 1$ & $8 \pm 1$ & $0.98 \pm 0.02$ \\
\hline $0.1 \mathrm{mM} \mathrm{PO}_{4}$ & $90 \pm 75$ & $2.6 \pm 0.2$ & $1.61 \pm 0.06$ & $0.99 \pm 0.02$ \\
\hline
\end{tabular}

$717{ }^{a}$ Second order kinetics fitting parameters for $\mathrm{Fe}(\mathrm{II})$-catalyzed Ni release from $\mathrm{Fe}(\mathrm{III})$ oxides (see 718 Electronic Annex).

$719{ }^{b}$ Fraction of initial incorporated Ni released from the mineral during reaction.

$720{ }^{c}$ Speciation of solid-associated $\mathrm{Ni}$ at the end of reaction as determined by LCF of Ni XANES 721 spectra. 
Table 3. Final fraction of solid-associated $\mathrm{Ni}$, corresponding Ni distributions, and $\mathrm{Fe}$ concentrations in the $\mathrm{Ni}$ incorporation experiments.

\begin{tabular}{|c|c|c|c|c|}
\hline Sample & f(Ni incorporated $)^{a}$ & {$[\mathbf{N i}]_{\text {inc }}(\mu \mathrm{M})^{b}$} & {$[\mathbf{N i}]_{\text {ads }}(\mu \mathbf{M})^{b}$} & {$[\mathbf{F e}]_{\mathrm{aq}}(\mu \mathbf{M})^{c}$} \\
\hline \multicolumn{5}{|c|}{$\overline{\text { Hematite Fe(II)-free }}$} \\
\hline Oxoanion-free & $0.004 \pm 0.002$ & $1 \pm 4$ & $174 \pm 4$ & $5 \pm 1$ \\
\hline $0.1 \mathrm{mM} \mathrm{PO}_{4}$ & $0 \pm 0.03$ & $0 \pm 6$ & $190 \pm 6$ & $\mathrm{BDL}^{\mathrm{d}}$ \\
\hline $0.5 \mathrm{mM} \mathrm{PO}_{4}$ & $0.02 \pm 0.03$ & $3 \pm 5$ & $196 \pm 5$ & BDL \\
\hline $0.1 \mathrm{mM} \mathrm{SO}_{4}$ & $0.02 \pm 0.02$ & $3 \pm 3$ & $170 \pm 3$ & BDL \\
\hline $1.0 \mathrm{mM} \mathrm{SO}_{4}$ & $0.09 \pm 0.02$ & $18 \pm 4$ & $170 \pm 4$ & $\mathrm{BDL}$ \\
\hline \multicolumn{5}{|c|}{ Hematite + $0.5 \mathrm{mMFe}($ II $)$} \\
\hline Oxoanion-free & $0.36 \pm 0.02$ & $67 \pm 4$ & $118 \pm 4$ & $195 \pm 7$ \\
\hline $0.1 \mathrm{mM} \mathrm{PO}_{4}$ & $0.17 \pm 0.04$ & $32 \pm 7$ & $158 \pm 7$ & $115 \pm 3$ \\
\hline $0.5 \mathrm{mM} \mathrm{PO}_{4}$ & $0.05 \pm 0.02$ & $10 \pm 4$ & $189 \pm 4$ & $6.4 \pm 0.1$ \\
\hline \multicolumn{5}{|c|}{ Hematite + $1.0 \mathrm{mMFe}(\mathrm{II})$} \\
\hline Oxoanion-free & $0.50 \pm 0.03$ & $92 \pm 6$ & $93 \pm 6$ & $403 \pm 3$ \\
\hline $0.1 \mathrm{mM} \mathrm{SO}_{4}$ & $0.48 \pm 0.03$ & $89 \pm 6$ & $96 \pm 6$ & $545 \pm 5$ \\
\hline $1.0 \mathrm{mM} \mathrm{SO}_{4}$ & $0.40 \pm 0.03$ & $75 \pm 5$ & $112 \pm 5$ & $430 \pm 6$ \\
\hline \multicolumn{5}{|c|}{ Goethite $\mathrm{Fe}(I I)$-free } \\
\hline Oxoanion-free & $0.17 \pm 0.02$ & $27 \pm 3$ & $138 \pm 3$ & BDL \\
\hline $0.1 \mathrm{mM} \mathrm{PO}_{4}$ & $0.14 \pm 0.03$ & $22 \pm 6$ & $138 \pm 7$ & BDL \\
\hline $0.5 \mathrm{mM} \mathrm{PO}_{4}$ & $0.04 \pm 0.03$ & $7 \pm 5$ & $180 \pm 6$ & BDL \\
\hline $0.1 \mathrm{mM} \mathrm{SO}_{4}$ & $0.25 \pm 0.02$ & $40 \pm 3$ & $120 \pm 3$ & $8 \pm 1$ \\
\hline $1.0 \mathrm{mM} \mathrm{SO}_{4}$ & $0.19 \pm 0.03$ & $29 \pm 4$ & $125 \pm 4$ & $23.9 \pm 0.5$ \\
\hline \multicolumn{5}{|c|}{ Goethite + 0.5 mM Fe(II) } \\
\hline Oxoanion-free & $0.44 \pm 0.02$ & $49 \pm 3$ & $63 \pm 3$ & $234 \pm 5$ \\
\hline $0.1 \mathrm{mM} \mathrm{PO}_{4}$ & $0.44 \pm 0.03$ & $52 \pm 4$ & $66 \pm 4$ & $214 \pm 5$ \\
\hline $0.5 \mathrm{mM} \mathrm{PO}_{4}$ & $0.32 \pm 0.02$ & $58 \pm 4$ & $126 \pm 6$ & $32.5 \pm 0.4$ \\
\hline \multicolumn{5}{|c|}{ Goethite + 1.0 mM Fe(II) } \\
\hline Oxoanion-free & $0.50 \pm 0.03$ & $52 \pm 3$ & $52 \pm 3$ & $638 \pm 16$ \\
\hline $0.1 \mathrm{mM} \mathrm{SO}_{4}$ & $0.62 \pm 0.03$ & $83 \pm 4$ & $50 \pm 4$ & $674 \pm 15$ \\
\hline $1.0 \mathrm{mM} \mathrm{SO}_{4}$ & $0.58 \pm 0.02$ & $74 \pm 4$ & $54 \pm 4$ & $657 \pm 9$ \\
\hline
\end{tabular}

${ }^{a}$ Fraction of solid-associated Ni incorporated into the Fe(III) oxide, calculated by LCF of

725 XANES spectra. Component sums of $\mathrm{f}(\mathrm{Ni}$ incorporated) and $\mathrm{f}(\mathrm{Ni}$ adsorbed) are included in the

726 Electronic Annex (Table EA2).

$727{ }^{b}$ Concentration of $\mathrm{Ni}$ that is incorporated or adsorbed, calculated using final aqueous $\mathrm{Ni}$

728 concentrations determined by ICP-OES and the LCF XANES spectral fits.

$729{ }^{c}$ Concentration of $\mathrm{Fe}$ remaining in solution at the end of the 30-day $\mathrm{Ni}$ incorporation

730 experiments, determined by ICP-OES of the filtrate.

$731{ }^{d}$ Measured analyte below detection limit (BDL). 
Figure 1. Ni adsorption isotherms at pH 7 on Hem (A) and Goe (B). Lines represent Langmuir isotherm fits to the data.

Figure 2. Ni fluorescence EXAFS spectra (points) and structural model fits (red lines) for $\mathrm{Ni}$ adsorbed onto hematite $(\mathrm{A}, \mathrm{B})$ and goethite $(\mathrm{C}, \mathrm{D})$ with (i) $0.1 \mathrm{mM}$ phosphate and $1 \mathrm{~g} \mathrm{~L}^{-1} \mathrm{Fe}(\mathrm{III})$ oxide, (ii) $0.5 \mathrm{mM}$ phosphate and $4 \mathrm{~g} \mathrm{~L}^{-1} \mathrm{Fe}$ (III) oxide, (iii) $0.1 \mathrm{mM}$ sulfate and $1 \mathrm{~g} \mathrm{~L}^{-1} \mathrm{Fe}$ (III) oxide, and (iv) $1.0 \mathrm{mM}$ sulfate and $4 \mathrm{~g} \mathrm{~L}^{-1} \mathrm{Fe}$ (III) oxide.

Figure 3. Ni release at $\mathrm{pH} 7$ from NiHem (A) and NiGoe (B). Filled symbols represent samples reacted with $1 \mathrm{mM} \mathrm{Fe}(\mathrm{II})$; open symbols represent samples reacted in the absence of $\mathrm{Fe}(\mathrm{II})$. Lines represent second-order kinetic fits to the data.

Figure 4. Ni fluorescence XANES of standards used for LCF fitting of Ni release experiments with goethite (A) or hematite (B): Adsorbed $\mathrm{Ni}$ with $0.1 \mathrm{mM}$ phosphate (i) or $0.1 \mathrm{mM}$ sulfate (ii), and incorporated Ni (iii); and XANES (points) and LCF fits (red lines) for solids collected at the end of Ni release experiments at $\mathrm{pH} 7.5$ with NiGoe (C) and NiHem (D) for samples reacted with $0.1 \mathrm{mM}$ phosphate (i), with $0.1 \mathrm{mM}$ sulfate (ii), and without oxoanions (iii).

Figure 5. Ni XANES spectra of standards used for LCF fitting of Ni incorporation experiments with goethite (A) or hematite (B): Adsorbed Ni with $0.5 \mathrm{mM}$ phosphate (i) or $1.0 \mathrm{mM}$ sulfate (ii), and incorporated Ni (iii); XANES spectra (points) and LCF fits (red lines) for Ni incorporation experiments at $\mathrm{pH} 7.5$ without Fe(II) [Goe (C) and Hem (D)] and with Fe(II) [Goe (E) and Hem (F)] reacted for 30 days with $0.1 \mathrm{mM}$ phosphate (i), $0.5 \mathrm{mM}$ phosphate (ii), $0.1 \mathrm{mM}$ sulfate (iii), $1.0 \mathrm{mM}$ sulfate (iv), without oxoanions (v) [and $0.5 \mathrm{mM} \mathrm{Fe}(\mathrm{II})$ in $\mathrm{E}$ and $\mathrm{F}$ ], or (vi) without oxoanions and $1.0 \mathrm{mM} \mathrm{Fe}(\mathrm{II})$.

759 

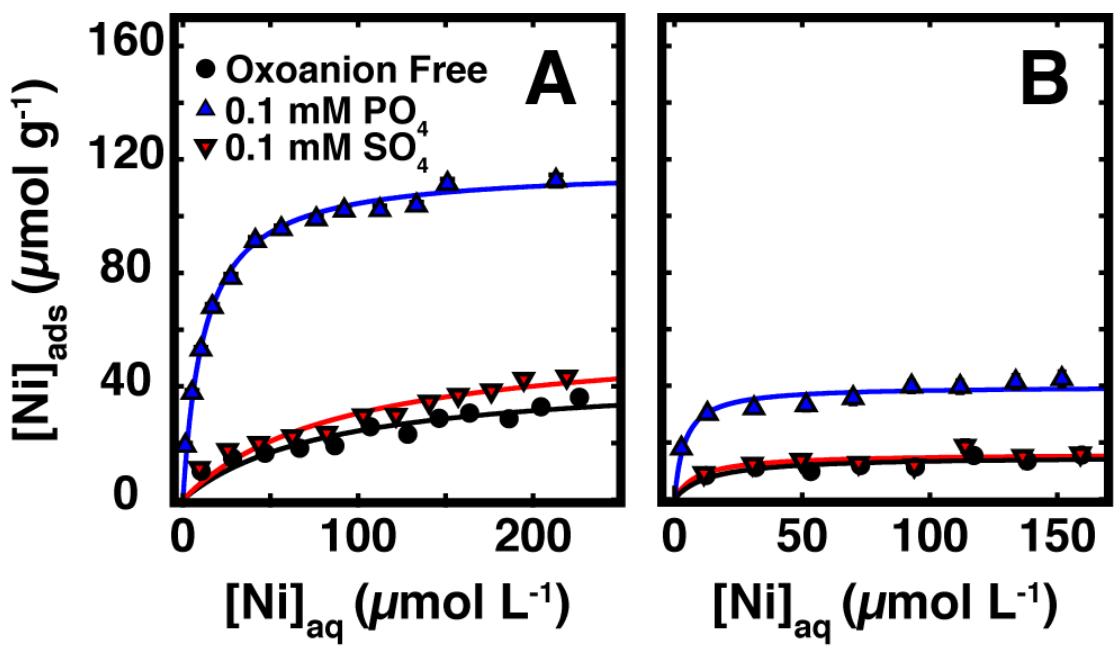

763 Figure 1. Ni adsorption isotherms at $\mathrm{pH} 7$ on Hem (A) and Goe (B). Lines represent Langmuir 764 isotherm fits to the data. 

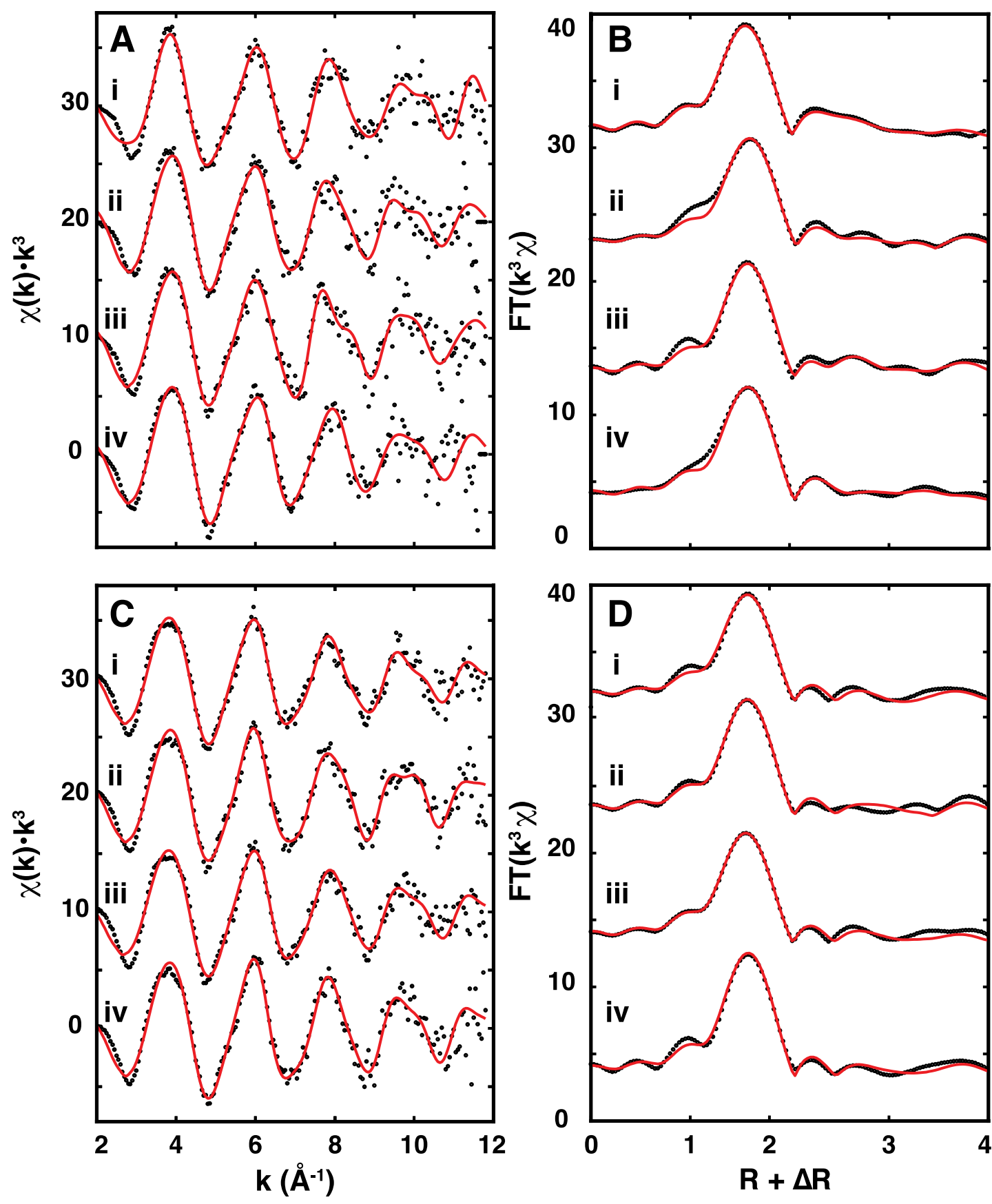

766 Figure 2. Ni fluorescence EXAFS spectra (points) and structural model fits (red lines) for $\mathrm{Ni}$ adsorbed onto hematite (A, B) and goethite (C, D) with (i) $0.1 \mathrm{mM}$ phosphate and $1 \mathrm{~g} \mathrm{~L}^{-1} \mathrm{Fe}(\mathrm{III})$ oxide, (ii) $0.5 \mathrm{mM}$ phosphate and $4 \mathrm{~g} \mathrm{~L}^{-1} \mathrm{Fe}$ (III) oxide, (iii) $0.1 \mathrm{mM}$ sulfate and $1 \mathrm{~g} \mathrm{~L}^{-1} \mathrm{Fe}$ (III) oxide, and (iv) $1.0 \mathrm{mM}$ sulfate and $4 \mathrm{~g} \mathrm{~L}^{-1} \mathrm{Fe}$ (III) oxide. 

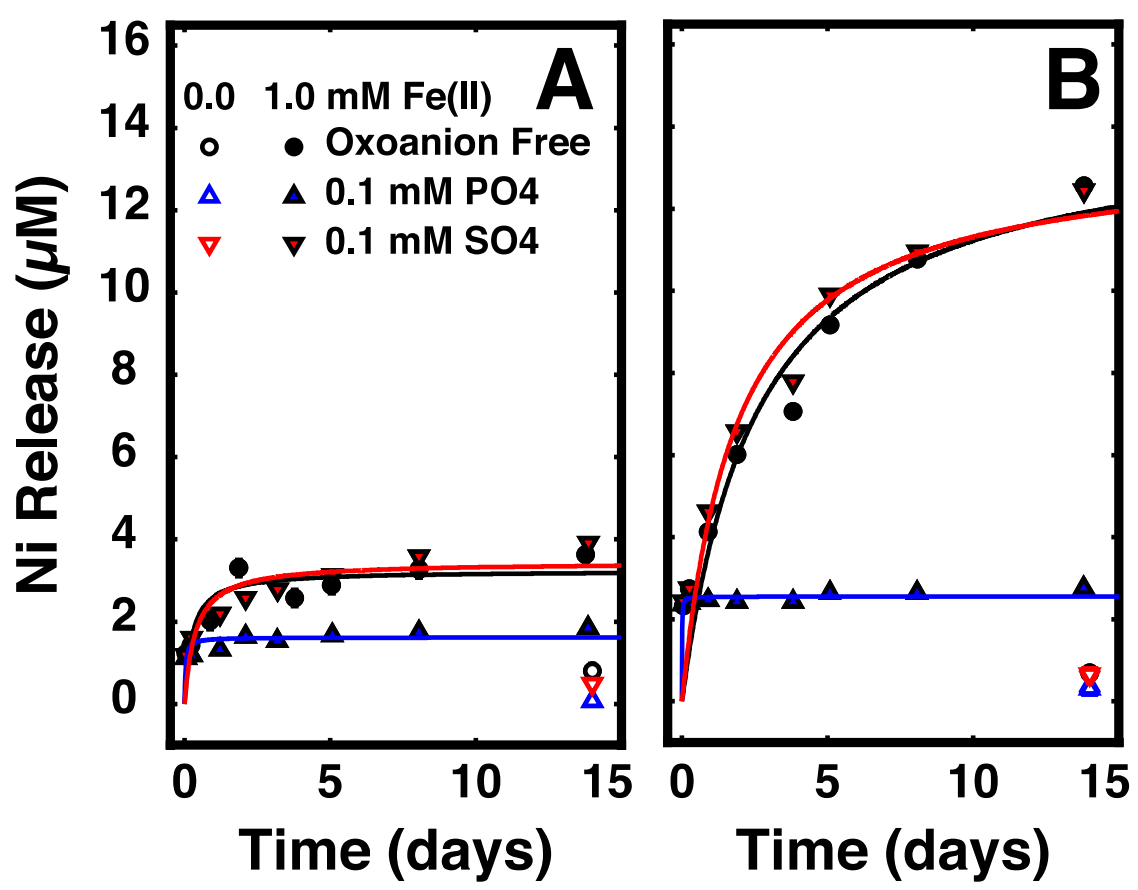

771 Figure 3. Ni release at $\mathrm{pH} 7$ from NiHem (A) and NiGoe (B). Filled symbols represent samples

772 reacted with $1 \mathrm{mM} \mathrm{Fe}(\mathrm{II})$; open symbols represent samples reacted in the absence of $\mathrm{Fe}$ (II).

773 Lines represent second-order kinetic fits to the data. 

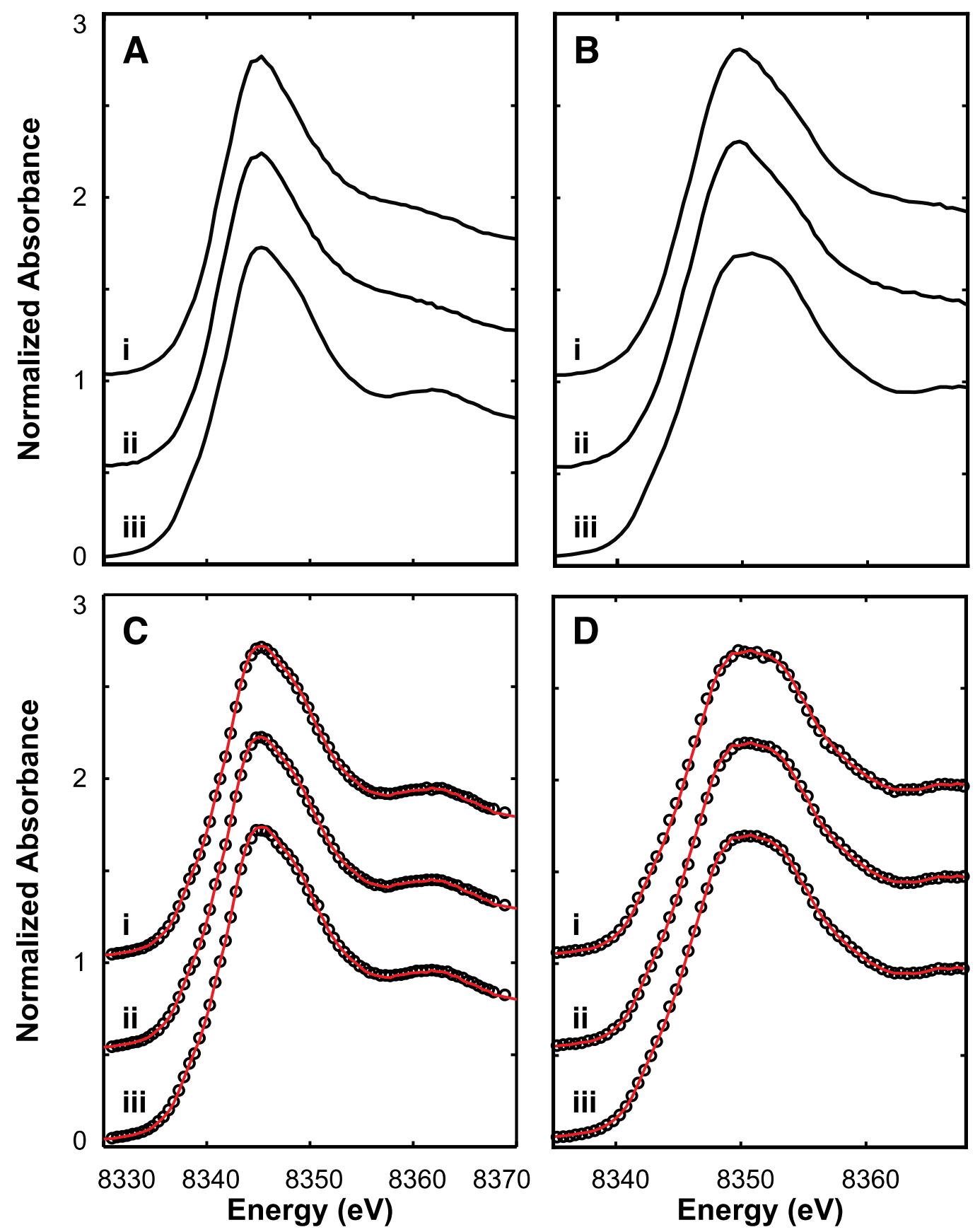

775 Figure 4. Ni fluorescence XANES of standards used for LCF fitting of Ni release experiments with goethite (A) or hematite (B): Adsorbed Ni with $0.1 \mathrm{mM}$ phosphate (i) or $0.1 \mathrm{mM}$ sulfate (ii), and incorporated Ni (iii); and XANES (points) and LCF fits (red lines) for solids collected at the end of Ni release experiments at $\mathrm{pH} 7.5$ with $\mathrm{NiGoe}$ (C) and NiHem (D) for samples reacted with 

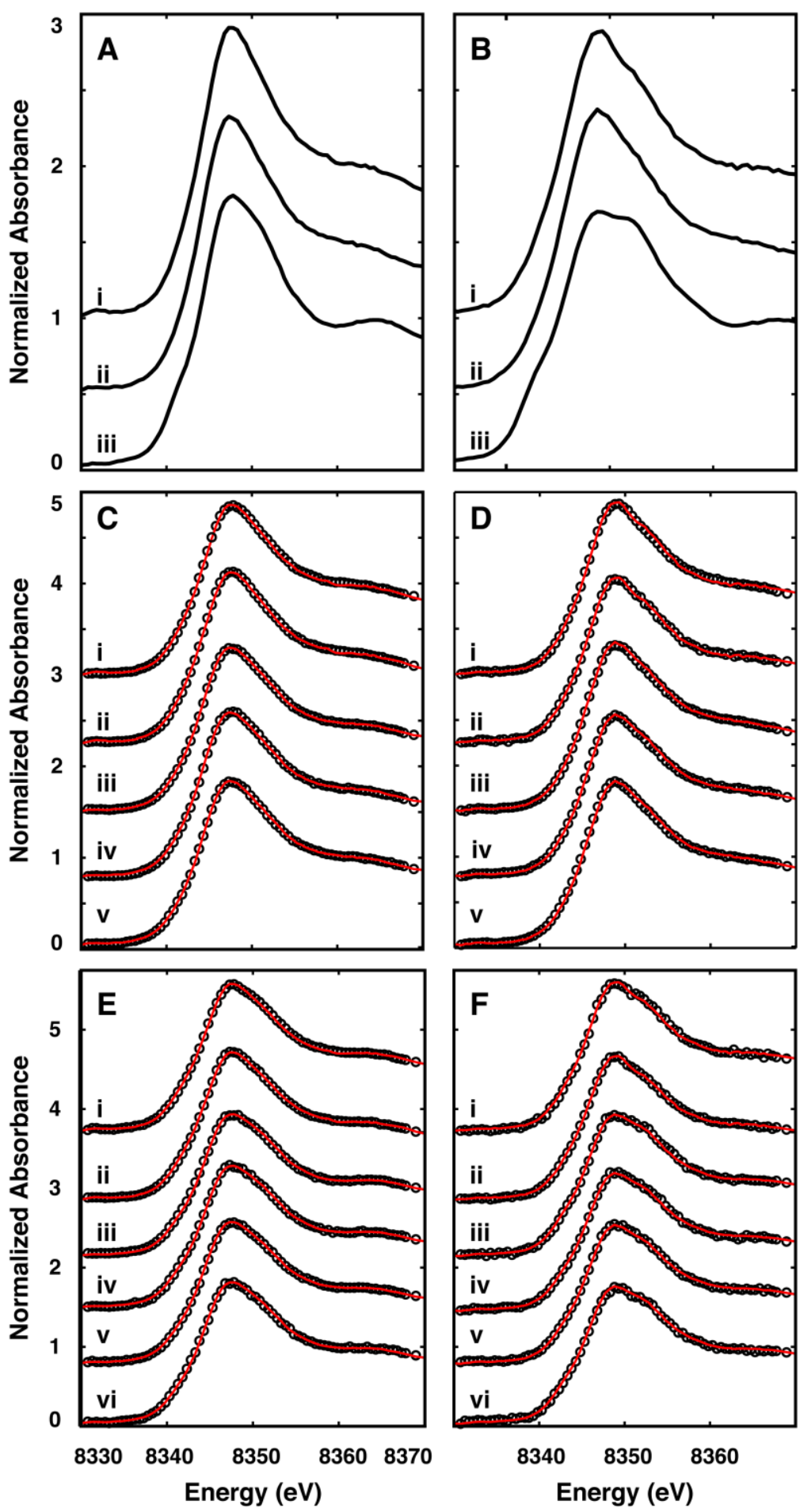

Figure 5. Ni XANES spectra of standards used for LCF fitting of Ni incorporation experiments with goethite (A) or hematite (B): Adsorbed Ni with $0.5 \mathrm{mM}$ phosphate (i) or $1.0 \mathrm{mM}$ sulfate (ii), and incorporated Ni (iii); XANES spectra (points) and LCF fits (red lines) for Ni incorporation experiments at $\mathrm{pH} 7.5$ without $\mathrm{Fe}(\mathrm{II})$ [Goe (C) and Hem (D)] and with Fe(II) [Goe (E) and Hem (F)] reacted for 30 days with $0.1 \mathrm{mM}$ phosphate (i), $0.5 \mathrm{mM}$ phosphate (ii), $0.1 \mathrm{mM}$ sulfate (iii), $1.0 \mathrm{mM}$ sulfate (iv), without oxoanions (v) [and $0.5 \mathrm{mM} \mathrm{Fe}$ (II) in $\mathrm{E}$ and F], or (vi) without oxoanions and $1.0 \mathrm{mM} \mathrm{Fe}(\mathrm{II})$. 